\title{
BMJ Open Does a healthy lifestyle behaviour influence the prognosis of low back pain among men and women in a general population? A population-based cohort study
}

\author{
Tony Bohman, ${ }^{1}$ Lars Alfredsson, ${ }^{1,2}$ Irene Jensen, ${ }^{1}$ Johan Hallqvist, ${ }^{3,4}$ Eva Vingård, ${ }^{5}$ \\ Eva Skillgate ${ }^{1,6}$
}

To cite: Bohman T,

Alfredsson L, Jensen I, et al. Does a healthy lifestyle behaviour influence the prognosis of low back pain among men and women in a general population? A population-based cohort study. BMJ Open 2014;4: e005713. doi:10.1136/ bmjopen-2014-005713

- Prepublication history and additional material is available. To view please visit the journal (http://dx.doi.org/ 10.1136/bmjopen-2014005713).

Received 16 May 2014 Revised 22 October 2014 Accepted 3 November 2014

CrossMark

For numbered affiliations see end of article.

Correspondence to Dr Tony Bohman; tony.bohman@ki.se

\section{ABSTRACT}

Objectives: To study the influence of healthy lifestyle behaviour on the prognosis of occasional low back pain among men and women in a general population. Design: Cohort study with a 4-year follow-up. Settings: General population in Stockholm County, Sweden.

Participants: The study sample comprised 3938 men and 5056 women aged 18-84 from the Stockholm Public Health Cohort reporting occasional low back pain in the baseline questionnaire 2006.

Measures: Lifestyle factors and potential confounders were assessed at baseline. The lifestyle factors smoking habits, alcohol consumption, leisure physical activity and consumption of fruit and vegetables were dichotomised using recommendations for a healthenhancing lifestyle and combined to form the exposure variable 'healthy lifestyle behaviour'. The exposure was categorised into five levels according to the number of healthy lifestyle factors met. The follow-up questionnaire in 2010 gave information about the outcome, long duration troublesome low back pain. Crude and adjusted binomial regression models were applied to estimate the association between the exposure and the outcome analysing men and women separately.

Results: The risk of developing long duration troublesome low back pain among women with occasional low back pain decreased with increasing healthy lifestyle behaviour (trend test: $p=0.006$ ). $21 \%$ $(28 / 131)$ among women with no healthy lifestyle factor (reference) experienced the outcome compared to $9 \%$ (36/420) among women with all four factors. Compared to the reference group, the risk was reduced by $35 \%$ (RR $0.65,95 \% \mathrm{Cl} 0.44$ to 0.96 ) for women with one healthy lifestyle factor and $52 \%$ (RR $0.48,95 \% \mathrm{Cl} 0.31$ to 0.77 ) for women with all four healthy lifestyle factors. There were no clear associations found among men.

Conclusions: Healthy lifestyle behaviour seems to decrease the risk of developing long duration troublesome low back pain among women with occasional low back pain and may be recommended to improve the prognosis.

\section{Strengths and limitations of this study}

- The strengths of this study are the large sample, the longitudinal design, the long-term follow-up, robust analyses and the large number of potential confounding factors assessed.

- The possible limitations of this study were the potential risk of misclassification of the exposure variable and the relatively large loss to follow-up, although these limitations most probably lead to an underestimation of the associations studied. Further, the results may have been affected by questionnaire items not fully validated.

\section{INTRODUCTION}

Lifestyle factors such as non-smoking, physical activity, healthy diet and moderate alcohol use seem to influence the risk and the prognosis in several diseases (eg, cancer, type 2 diabetes mellitus and cardiovascular disease) as well as mortality, especially when the factors are combined. ${ }^{1-5}$

Low back pain (LBP) is one of the most common health problems worldwide and comprises a large burden on individuals as well as on society. ${ }^{6}{ }^{7}$ When estimating the global prevalence of activity-limiting LBP using 165 studies from 54 countries, Hoy and colleagues found the mean point and 1 month prevalence to be $11.9 \pm 2.0 \%$ and $23.2 \pm 2.9 \%$, respectively. ${ }^{6}$ Current knowledge of prognostic factors, for example, lifestyle factors, for LBP is limited and the aforementioned facts support the need for more research on this topic.

In a 'review of reviews' from 2009, Hayden and colleagues reported older age, negative cognitive characteristics, poor general health, increased psychological or psychosocial stress, poor relations with colleagues, physically 
heavy work, functional disability, sciatica, and the presence of workers' compensation to be associated with poor outcomes of acute and subacute LBP. $^{8}$ Another 2009 review found recovery expectations to be associated with activity limitations or participation restrictions (eg, return to work) in persons with non-chronic non-specific LBP. $^{9}$ In the review by Hayden and colleagues, smoking was the only lifestyle factor included and found by two studies to have no association with poor outcomes of acute and sub acute LBP. ${ }^{8}$ Similarly, a recent review studying prognostic factors for recovery from chronic LBP found no association between smoking and the outcome pain and disability. ${ }^{10}$ Moreover, on reviewing observational studies on patients with LBP, Hendrick and colleagues found moderate evidence for sports, leisure and occupational physical activity not to be associated with LBP outcomes. ${ }^{11}$

Women seem to have higher prevalence, be more severely affected and have a worse prognosis of LBP than men, and some studies suggest that men and women should be assessed separately when studying risk and prognostic factors for LBP. ${ }^{612-14}$

To the best of our knowledge, it is not known if healthy lifestyle behaviour (HLB), defined by a combination of lifestyle factors, is associated with the prognosis of LBP. HLB seems to have a larger potential to affect health problems and mortality than separate lifestyle factors alone. ${ }^{1-5}$ We hypothesised that HLB would decrease the risk of a poor outcome among men and women with occasional LBP. If HLB affects the prognosis of LBP, implementing this knowledge could potentially prevent transition into disabling LBP and thereby reduce the burden on the individual as well as on the society.

The aim of this study was to explore the influence of HLB on the prognosis of occasional LBP among men and women in a general population, hypothesising that HLB can improve the prognosis.

\section{METHODS}

\section{Study design and source population}

In this study, we used data from the Stockholm Public Health Cohort (SPHC). ${ }^{15}$ SPHC was set up by the Stockholm County Council and administered by Statistics Sweden and the Department of Public Health Sciences at Karolinska Institutet, Stockholm. SPHC is a population-based cohort established within the framework of the Stockholm County Council public health surveys. In 2006, Stockholm County had an adult population of approximately 1.4 million individuals. From this population, a total of 56634 individuals (1884 years old) were randomly selected, after stratification for gender and residential area, and received the baseline questionnaire, which $34707(61 \%)$ answered. The responders received a follow-up questionnaire in 2010, answered by 25167 participants (73\%). Compared to consensus data from Stockholm County, the SPHC participants were more likely to be women, be born in Sweden, have higher education and income and be more than 45 years old. ${ }^{15}$

\section{Study sample}

The study sample $(n=8994)$ consisted of participants reporting occasional LBP at baseline in 2006 who answered the follow-up questionnaire in 2010 and provided complete information on outcome and exposure variables (figure 1). Occasional LBP at baseline was defined as reporting having had LBP, on average, up to a few days per month during the past 6 months (for the item used to define occasional LBP, see online supplementary appendix 1). The information was based on a modified version of a question from the Standardized Nordic Questionnaire. ${ }^{16}$

\section{Data collection and variables}

The baseline and the follow-up questionnaires comprised self-reported information on lifestyle, demographic and socioeconomic characteristics, physical and psychological health and work-related factors. The selfreported data were supplemented with information from regional and national registers. ${ }^{15}$ Four reminders were sent after the baseline questionnaire and three reminders after the follow-up questionnaire.

\section{Exposure: HLB}

Using baseline information, we constructed four binary healthy lifestyle factors where cut-offs (healthy/not healthy) were set in accordance with recommendations for a health-enhancing lifestyle made by Swedish authorities and WHO. ${ }^{17-20}$ The exposure variable 'healthy lifestyle behaviour' (HLB) was a combination of these binary factors and was categorised into five levels according to the number of healthy lifestyle factors included, that is, from none to four (HLB0 to HLB4). A HLB with regard to each of the considered healthy factors was defined by: non-smoking, no risk consumption of alcohol $(\leq 168 \mathrm{~g} 100 \%$ alcohol/week for men and $\leq 108 \mathrm{~g} 100 \%$ alcohol/week for women, and consuming alcohol corresponding to about half a bottle of spirits $(35 \mathrm{cL})$ on the same occasion less than once a month), recommended level of leisure physical activity (at least $150 \mathrm{~min}$ at moderate intensity or $75 \mathrm{~min}$ at high intensity per week or a combination of these activities), and recommended consumption of fruit and vegetables $(\geq \mathrm{a}$ total of 4 servings of fruit and vegetables per day, equal to about $400 \mathrm{~g} /$ day) (see online supplementary appendix 2 for a description of the questions and how the variables were constructed).

\section{Outcome variable: Iong duration troublesome LBP}

Information on the outcome long duration troublesome LBP (LTLBP) was collected from the follow-up questionnaire in 2010 and defined as having had LBP that decreased workability or interfered with other daily activities to some or to a high degree, on average a few days 


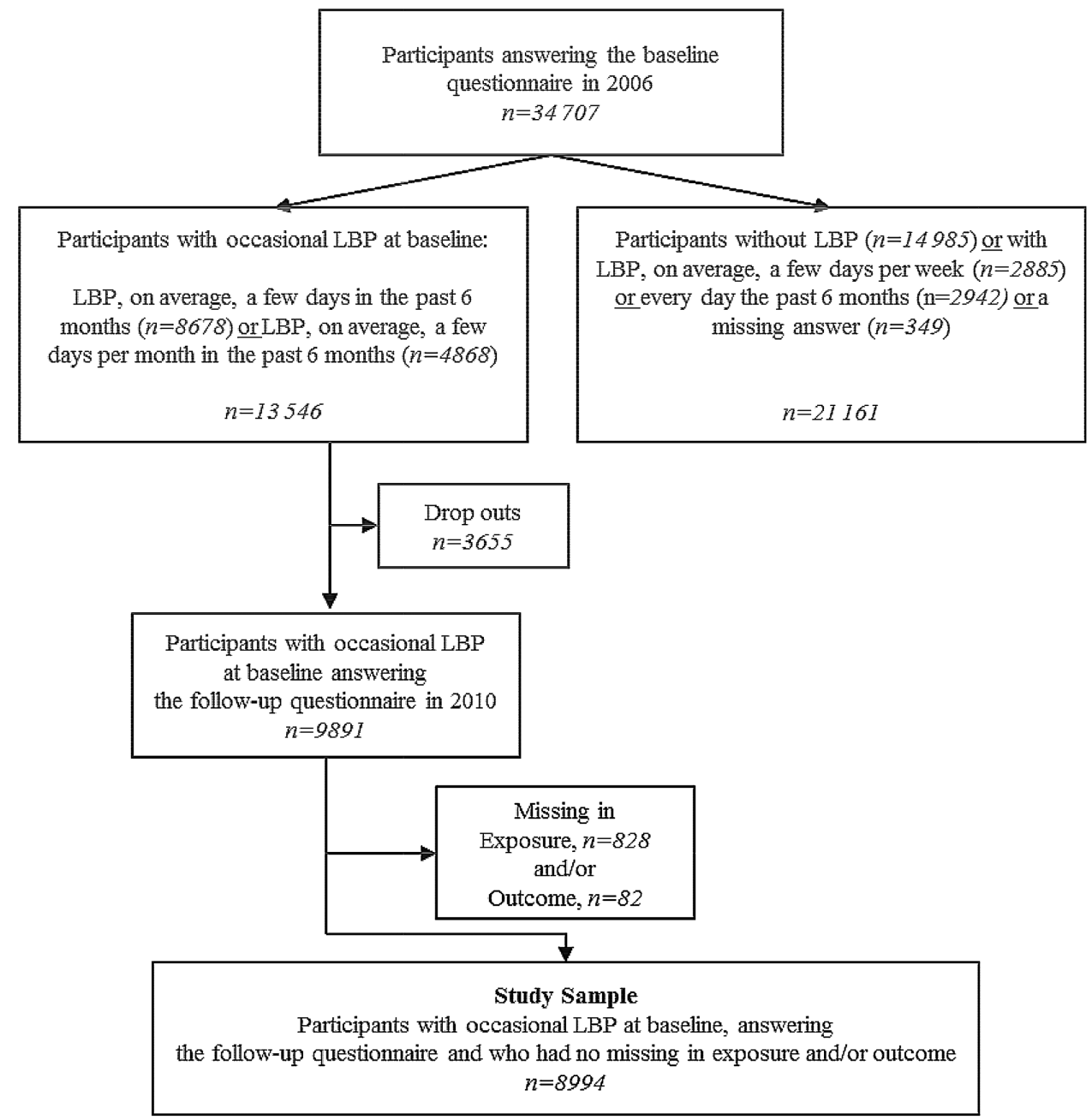

Figure 1 Flow chart of the inclusion process for the study sample (LBP, low back pain).

per week or more often during the past 6 months (for the items used to define LTLBP, see online supplementary appendix 1). The question used to measure LTLBP was modified from the Standardized Nordic Questionnaire and incorporated a dimension of disability suggested to be of importance when defining LBP. ${ }^{16} 21$

\section{Potential confounding factors}

Potential confounders were chosen based on theoretical and empirical relevance, as well as information from literature regarding the prognosis of spinal pain and availability in the questionnaire. ${ }^{82} 23$ The following factors were considered: long-term illness (suffering from long-term illness, health problems following an accident, disability or other persistent health problems), neck pain and pain from hip, thigh or knee during the past 6 months (5 answer alternatives from 'no pain' to 'daily pain'), suffering from a headache or migraine ('no', 'somewhat' to 'severe'), rheumatoid arthritis diagnosed by a physician, living alone, living with children (children of all ages included) and hours of sleep on a typical night during the workweek (dichotomised into 'good sleep': 6-8 h and 'poor sleep': $<6$ or $>8 \mathrm{~h}$ ). The questionnaire also included the 12-item General Health Questionnaire where a sum score of $\geq 3$ (using the recommended 0-0-1-1 scoring on the four answer alternatives) was used to assess psychological distress. ${ }^{24}{ }^{25}$ The frequency of stress was measured by the question 'How often do you feel stress?' with five answer alternatives from 'never' to 'most of the week'. Personal support (having persons who can give support in handling personal problems or critical life events) was measured using a question from the Social Support-13 instrument (SS-13). ${ }^{26}$ Furthermore, financial stress was assessed by the question "Did it during the previous 12 months happen that you ran out of money and had to borrow from relatives and friends to be able to pay for food or rent?" ('no', 'yes, on one occasion', 'yes, on several occasions'). A Swedish National Register supplied information on civil status (married, unmarried, divorced, widow/ widower), country of birth (Sweden, Nordic countries and Europe, outside Europe), socioeconomic status (SES), annual individual disposable income (grouped in quintiles) and education. ${ }^{27} 28$ The level of education was categorised into low (only compulsory education and vocational training), intermediate (secondary school) and high (university studies). 


\section{Statistical methods}

We used generalised linear models with a binomial distribution to estimate the association between the exposure and the outcome analysing men and women separately. To determine the role of a potential confounding factor, we included them, one at a time, into the crude model. Only factors that changed the estimated risk ratio (RR) by $10 \%$ or more were entered into the final model. ${ }^{29-33}$ All final models were adjusted for age categorised into 10-year intervals. Age was categorised as it showed non-linearity with the outcome. We calculated RR, using the $\log$ function, as well as risk differences (RD), using the identity function, with $95 \%$ CI. A likelihood ratio test was used to assess clinically relevant effect measure modification between the exposure and possible confounders (age, education, SES, neck pain, long-term illness and psychological distress) as well as between confounders included in the adjusted models (age and SES) ${ }^{34}$ An effect measure modification significant at $\mathrm{p} \leq 0.05$ was included in further analyses. ${ }^{34}$ We used Wald's test to evaluate potential trends in the associations between the exposure and the outcome, and a $\chi^{2}$ test to assess if the overall adjusted risk differed between men and women. ${ }^{34}$ The effect of attrition was assessed, using $\chi^{2}$ tests, by comparing the distribution of the four healthy lifestyle factors included in the exposure, HLB, in participants who were lost to follow-up to the distribution in the study sample. All $p$ values were two sided, and analyses were completed using SAS V.9.3 and STATA/IC V.12.1.

\section{RESULTS}

\section{Baseline characteristics}

The study sample $(\mathrm{n}=8994)$ consisted of $56 \%$ women. Participants were predominantly middle aged, well educated and born in Sweden. At baseline in 2006, about $15 \%$ of the participants were 65 years or older (men $17 \%$ and women 14\%). Furthermore, the majority were cohabiting, and about $35 \%$ had children living at home (table 1). About $3 \%$ of men and $10 \%$ of women had an 'optimal healthy lifestyle' (HLB4), whereas about 5\% of men and $3 \%$ of women had an 'unhealthy lifestyle' (HLB0). HLB improved with increased level of education. Participants being married or having children living at home had a high proportion of HLB while participants living alone, being psychologically distressed and financially stressed showed low proportions of HLB (table 1).

The other baseline variables assessed did not differ much between the categories of HLB, neither among men nor among women.

The majority of men and women were non-smokers and did not exceed the risk consumption of alcohol. About $40 \%$ of both men and women reached recommended levels of leisure physical activity while $26 \%$ of the women consumed recommended levels of fruit and vegetables compared to $7 \%$ for men (figure 2 ).

\section{Outcome}

At follow-up in $2010,9 \%$ of men and $11 \%$ of women in the study sample reported LTLBP. Table 2 shows the crude and adjusted binomial regression estimations of the association between HLB and the outcome.

There was a decreased risk for LTLBP at follow-up for women with a HLB compared to women with unhealthy lifestyle behaviour (test for trend: $\mathrm{p}=0.006$ ). Twenty-one per cent of women with no healthy lifestyle factor (HLB0) experienced LTLBP at follow-up compared to $9 \%$ of women with all four factors (HLB4). A 5\% lower proportion of women with one healthy lifestyle factor, and an $8 \%$ lower proportion of women with all four factors had LTLBP, in comparison to the reference group (HLB0).Women with one healthy lifestyle factor and women with all four healthy lifestyle factors had a $35 \%$ and a $52 \%$ lower risk for LTLBP, respectively, compared to women with unhealthy lifestyle behaviour (HLB0). There were no clear associations between HLB and LTLBP found among men.

SES was the only variable found to be a confounder, so the final log-binomial analyses were adjusted by SES and age in 10-year categories. There was no clinically relevant effect measure modifications found.

Figure 3 shows the adjusted risk to develop LTLBP for men and women with occasional LBP by categories of HLB. Women had an overall higher adjusted risk for LTLBP than men $(\mathrm{p}=0.001)$.

The participants lost to follow-up $(n=4552)$ had significantly lower proportions of healthy lifestyle factors than the study sample $(\mathrm{p}<0.01$ for all four factors $)$. The differences in proportions were $8 \%$ for non-smoking, $16 \%$ for no risk consumption of alcohol, $6 \%$ for leisure physical activity and $5 \%$ for consumption of fruit and vegetables.

\section{DISCUSSION}

In this cohort study, we found that HLB had a positive influence on the prognosis of occasional LBP among women. HLB comprised four healthy lifestyle factors: non-smoking, no risk consumption of alcohol, recommended level of leisure physical activity and recommended consumption of fruit and vegetables. Compared to women with no healthy lifestyle factor, the risk for development of LTLBP decreased by $35 \%$ among women with one healthy lifestyle factor and by $52 \%$ among women with all four healthy lifestyle factors. In absolute terms, the proportion of women with LTLBP at follow-up was $5 \%$ lower if they had one healthy lifestyle factor and $8 \%$ lower if they had four healthy lifestyle factors when compared to women with unhealthy lifestyle behaviour. These associations were not confirmed among men, but the results indicated the same tendency.

Further, compared to women, men had an overall lower adjusted risk for LTLBP, and a low risk even in the unhealthy reference group (figure 3). Men with unhealthy lifestyle behaviour had about the same risk 


\begin{tabular}{|c|c|c|c|c|c|c|c|c|c|c|c|c|c|}
\hline \multirow[b]{2}{*}{$\begin{array}{l}\text { Baseline characteristics } \\
(\%)\end{array}$} & \multicolumn{6}{|l|}{ Men } & \multicolumn{6}{|l|}{ Women } & \multirow{2}{*}{$\begin{array}{l}\text { Internal } \\
\text { dropout } \\
\text { M/W (n) }\end{array}$} \\
\hline & $\begin{array}{l}\text { All } \\
(n=3938)\end{array}$ & $\begin{array}{l}\text { HLB0 } \\
(\mathrm{n}=181)\end{array}$ & $\begin{array}{l}\text { HLB1 } \\
(\mathrm{n}=958)\end{array}$ & $\begin{array}{l}\text { HLB2 } \\
(n=1747)\end{array}$ & $\begin{array}{l}\text { HLB3 } \\
(n=936)\end{array}$ & $\begin{array}{l}\text { HLB4 } \\
(n=116)\end{array}$ & $\begin{array}{l}\text { All } \\
(n=5056)\end{array}$ & $\begin{array}{l}\text { HLB0 } \\
(n=174)\end{array}$ & $\begin{array}{l}\text { HLB1 } \\
(n=897)\end{array}$ & $\begin{array}{l}\text { HLB2 } \\
(n=2080)\end{array}$ & $\begin{array}{l}\text { HLB3 } \\
(n=1416)\end{array}$ & $\begin{array}{l}\text { HLB4 } \\
(\mathrm{n}=489)\end{array}$ & \\
\hline Proportion of study sample & \multicolumn{6}{|l|}{44} & \multicolumn{7}{|l|}{56} \\
\hline Mean age, years (SD) & $50(15)$ & $49(14)$ & $48(15)$ & $49(15)$ & $51(15)$ & $50(14)$ & $46(16)$ & $43(17)$ & $47(15)$ & $46(16)$ & $47(15)$ & $46(14)$ & $0 / 0$ \\
\hline \multicolumn{13}{|l|}{ Education } & \multirow[t]{4}{*}{$234 / 287$} \\
\hline Low & 16 & 30 & 19 & 14 & 14 & 8 & 14 & 22 & 17 & 13 & 12 & 9 & \\
\hline Intermediate & 43 & 43 & 46 & 44 & 40 & 35 & 41 & 57 & 46 & 42 & 38 & 34 & \\
\hline High & 41 & 27 & 35 & 42 & 46 & 57 & 45 & 21 & 37 & 45 & 50 & 57 & \\
\hline \multicolumn{13}{|l|}{ Civil status } & \multirow[t]{4}{*}{$0 / 1$} \\
\hline Married & 54 & 42 & 49 & 56 & 56 & 65 & 47 & 27 & 41 & 46 & 53 & 53 & \\
\hline Unmarried & 33 & 38 & 36 & 32 & 31 & 29 & 36 & 49 & 37 & 37 & 33 & 32 & \\
\hline Divorced/widow/widower & 13 & 20 & 15 & 12 & 13 & 6 & 17 & 24 & 22 & 17 & 14 & 15 & \\
\hline \multicolumn{13}{|l|}{ SESt } & \multirow[t]{7}{*}{$292 / 398$} \\
\hline $\begin{array}{l}\text { Unskilled/semiskilled } \\
\text { worker }\end{array}$ & 14 & 22 & 17 & 13 & 12 & 9 & 16 & 23 & 19 & 16 & 14 & 10 & \\
\hline Skilled worker & 15 & 25 & 16 & 14 & 15 & 8 & 10 & 22 & 12 & 9 & 9 & 11 & \\
\hline $\begin{array}{l}\text { Assistant non-manual } \\
\text { employees }\end{array}$ & 8 & 8 & 10 & 9 & 7 & 5 & 20 & 22 & 21 & 22 & 18 & 15 & \\
\hline $\begin{array}{l}\text { Intermediate non-manual } \\
\text { employees }\end{array}$ & 25 & 14 & 25 & 24 & 27 & 24 & 29 & 23 & 23 & 29 & 31 & 35 & \\
\hline $\begin{array}{l}\text { Employed/self-employed } \\
\text { professionals }\end{array}$ & 25 & 17 & 18 & 28 & 28 & 34 & 19 & 7 & 17 & 18 & 21 & 24 & \\
\hline $\begin{array}{l}\text { Self-employed (other } \\
\text { than professionals) }\end{array}$ & 13 & 14 & 14 & 12 & 11 & 20 & 6 & 3 & 8 & 6 & 7 & 5 & \\
\hline \multicolumn{13}{|l|}{ Poor sleep $\ddagger$} & \multirow[t]{2}{*}{$34 / 27$} \\
\hline$<6$ or $>8$ h/night & 9 & 17 & 9 & 10 & 7 & 9 & 10 & 14 & 11 & 11 & 9 & 7 & \\
\hline Living alone & 17 & 31 & 19 & 16 & 14 & 9 & 19 & 24 & 21 & 19 & 17 & 17 & $10 / 16$ \\
\hline Living with children & 34 & 24 & 31 & 35 & 34 & 42 & 38 & 27 & 32 & 39 & 41 & 41 & $10 / 16$ \\
\hline Psychological distress§ & 13 & 18 & 15 & 13 & 11 & 5 & 21 & 33 & 23 & 22 & 19 & 17 & $38 / 37$ \\
\hline Financial stress $\uparrow$ & 7 & 15 & 10 & 5 & 4 & 3 & 9 & 23 & 13 & 9 & 7 & 6 & $17 / 24$ \\
\hline \multicolumn{14}{|c|}{$\begin{array}{l}\text { 'HLBO=no healthy lifestyle factor, HLB1=1 of } 4 \text { healthy lifestyle factors, HLB2=2 of } 4 \text { factors, HLB3 }=3 \text { of } 4 \text { factors, HLB } 4=\text { all } 4 \text { healthy lifestyle factors. } \\
\text { tSocioeconomic status (SES). For the economically active population, SES was based on current occupation and education. For the non-active population, SES was based on previous } \\
\text { occupation, current education or the occupation of spouses. } \\
\text { fHours of sleep on a typical night during the workweek (dichotomised into 'good sleep': } 6-8 \mathrm{~h} \text { and 'poor sleep': }<6 \text { or }>8 \mathrm{~h} \text { ). } \\
\text { \$From the } 12 \text {-item General Health Questionnaire (GHQ-12) where a sum score } \geq 3 \text { was used to assess psychological stress. } \\
\text { १Financial stress: had to borrow money from relatives and friends to be able to pay for food or rent on several occasions during the previous } 12 \text { months. }\end{array}$} \\
\hline
\end{tabular}




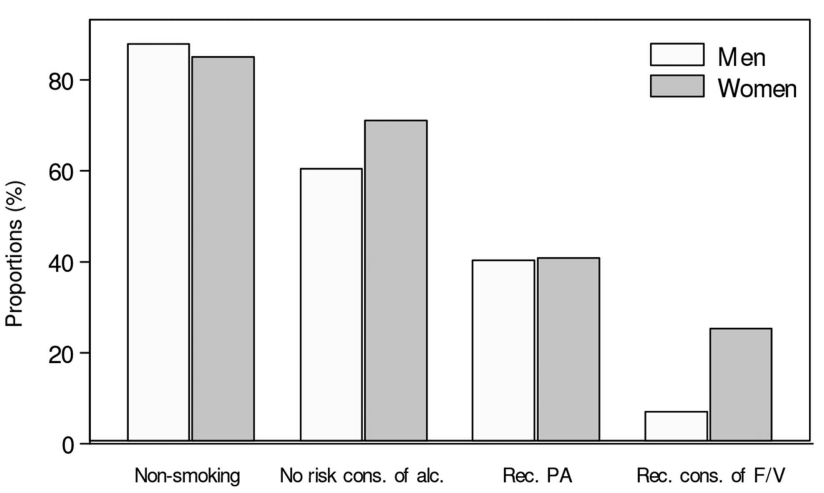

Figure 2 Distribution of healthy lifestyle factors (PA, leisure physical activity; F/V, fruit and vegetables).

for LTLBP as women with optimal HLB. These findings were not aimed to be addressed in the present study and need to be investigated further.

We found no studies concerning the effects of HLB, defined as a combination of healthy lifestyle factors, on the prognosis of LBP or other types of spinal pain. Nevertheless, considering the risk of developing chronic back pain, Pronk et $a l^{2}$ showed results in line with our study. ${ }^{2}$ Studying employees, the authors found that an 'optimal lifestyle' decreased the 2-year risk of chronic LBP by $66 \%$ compared to employees with an unhealthy lifestyle. Having an optimal lifestyle was equal to having all four of the healthy lifestyle factors, similar to the ones included in our study: non-smoking, adequate physical activity, five servings of fruit and vegetables per day and limited or no alcohol consumption.

\section{Strengths and limitations}

To the best of our knowledge, this is the first study concerning the influence of HLB on the prognosis of LBP assessing men and women separately. Measuring the exposure prior to the outcome and the dose-response relationship found supports the validity of the associations between HLB and LTLBP found among women. ${ }^{32}$ We believe that the use of a complete study sample, the large sample size and the large number of potential confounders assessed strengthens the internal validity, though we cannot rule out residual or unmeasured confounding, for example, information on healthcare services. ${ }^{32}$ The questions used in this study have, since 1975 , been used in several Swedish national and local public health surveys. They have on several occasions been tested (eg, cognitive testing) and improved by Statistics Sweden's test centre and several questions have shown acceptable psychometric properties. Moreover, information on education, disposable income, SES, country of birth and marital status were collected from Swedish National Registers known to have high quality. The questions concerning leisure physical activity and consumption of fruit and vegetables have shown acceptable validity and reliability, and the method to measure alcohol consumption has been recommended by

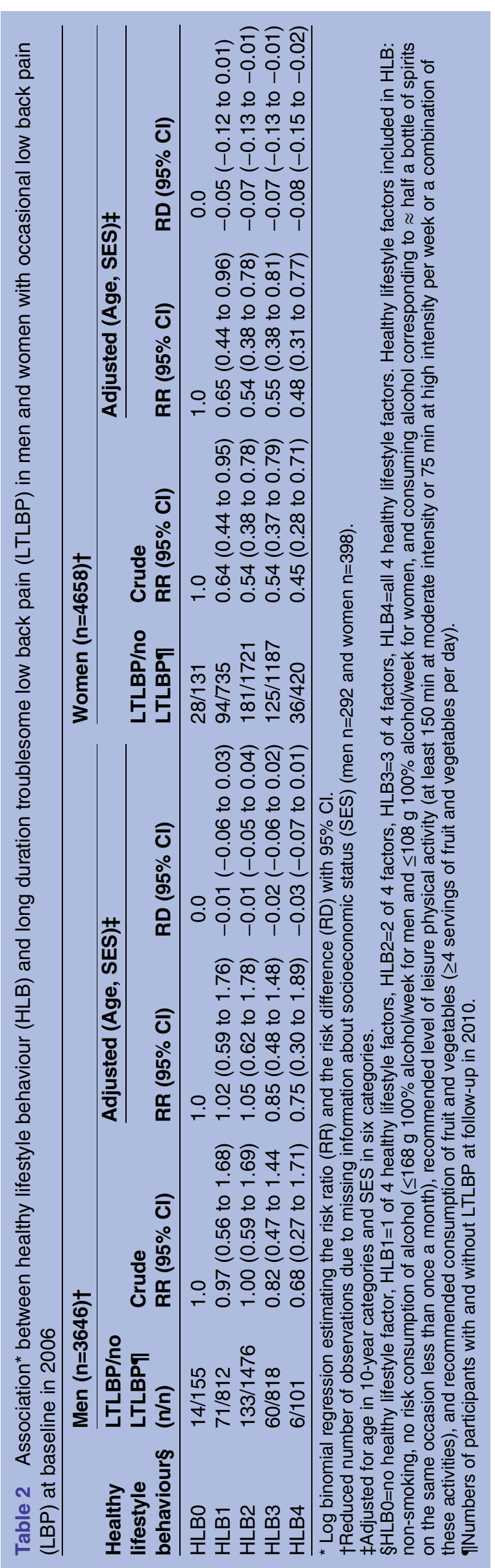


Figure 3 Estimated risk for long duration troublesome low back pain (LTLBP), adjusted for socioeconomic status (SES) and age (men $(n=3646)$, women $(n=4658))$.

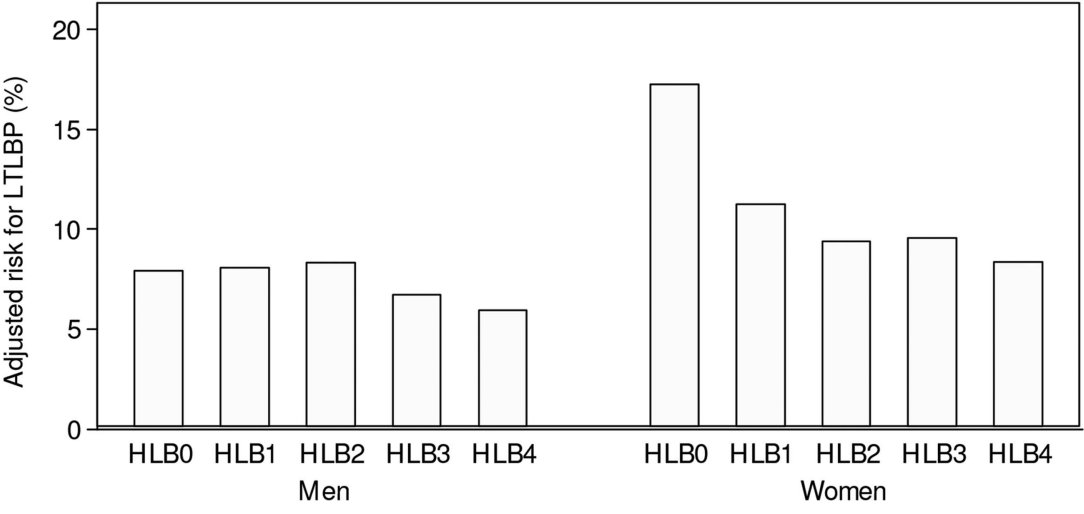

Romelsjö and colleagues. ${ }^{35-38}$ Despite this, the measurements used may not have been optimal in terms of validity and reliability.

Our study also has limitations. Self-reported exposure information may be hampered by low accuracy. For example, some participants may wish to present themselves in a favourable light and overestimate their healthy lifestyle (social desirability) or some may have difficulties understanding the questions and therefore report less well. ${ }^{32} 3940$ This could lead to misclassification of the exposure, which may result in an underestimation or overestimation of the association. As this potential misclassification is likely to be non-differential, it would probably dilute a true association, at least when comparing extremes. ${ }^{32}$ Moreover, if men tend to misclassify their healthy lifestyle factors to a greater extent than women, this may partly explain why we did not find any associations among men. For example, Dyrstad et at ${ }^{41}$ found that men overestimated their self-reported physical activity when compared to accelerometer measures to a greater extent than women. As we studied a population between 18 and 84 years old, a large proportion of the participants did not work. Therefore, we could not assess potential confounding effects from work related variables, something that may have affected the results. About $34 \%$ of the participants in the baseline survey were not part of the study sample due to attrition and exclusion (figure 1). Compared to the study sample, the $34 \%$ missing had the same proportion of men and women, were younger (the mean age for both sexes were 43 years) and both men and women had a slightly lower level of education as well as SES. Further, they had significantly lower proportions of healthy lifestyle factors than the study sample. This difference may have introduced selection bias to our results if the attrition and the loss to follow-up are related to the exposure as well as to the outcome. If selection bias is present, we believe that it probably leads to an underestimation of the associations, since these subjects to a higher extent may have developed LTLBP.

Considering the strengths and limitations in our study, we regard our result as a valid contribution to the body of research showing that a healthy lifestyle can have positive effects on several health problems. ${ }^{1-5}$ Our study results showing that HLB influences the prognosis of LBP are new and important knowledge with the potential to have an impact on a very common public health problem and have implications both in a public health and a clinical perspective. Even though the association for HLB to affect LBP among men was not clear, the results showed the same tendency as for women. Considering this together with the obvious effect of a healthy lifestyle on other health problems, the work to encourage both men and women to adapt a healthy lifestyle should certainly be continued.

\section{CONCLUSION}

HLB, defined as combinations of non-smoking, no risk consumption of alcohol, recommended level of leisure physical activity and recommended consumption of fruit and vegetables, seems to decrease the risk of developing long duration troublesome low back pain among women with occasional LBP. There were no clear associations found among men.

\section{Author affiliations}

${ }^{1}$ Institute of Environmental Medicine, Karolinska Institutet, Stockholm, Sweden

${ }^{2}$ Centre for Occupational and Environmental Medicine, Stockholm County Council, Stockholm, Sweden

${ }^{3}$ Department of Public Health Sciences, Karolinska Universitetssjukhuset, Stockholm, Sweden

${ }^{4}$ Department of Public Health and Caring Sciences, Uppsala University, Uppsala, Sweden

${ }^{5}$ Department of Medical Science, Uppsala University, Uppsala, Sweden ${ }^{6}$ Scandinavian College of Naprapathic Manual Medicine, Stockholm, Sweden

Acknowledgements The authors would like to thank Professor Matteo Bottai at the Institute of Environmental Medicine, Karolinska Institutet for advice regarding the statistical analyses, and Assistant Professor Jill Hayden at the Faculty of Medicine, Dalhousie University for valuable comments on the manuscript.

Contributors TB, ES, LA, EV and IJ contributed to the design of the study. $\mathrm{JH}$ and LA were part of the expert group responsible for the design and implementation of the SPHC. TB made the statistical analyses and wrote the first manuscript version. All authors contributed to the interpretation of the data and critically revised all versions of the manuscript and finally approved the last version.

Funding The Stockholm County Council provided the financial support to form The Stockholm Public Health Cohort. TB had his salary provided by The Health 
Care Sciences Postgraduate School at Karolinska Institutet, Stockholm, Sweden. ES was financially supported by the AFA Insurance postdoc scholarship.

Competing interests None.

Ethics approval The regional ethical review board in Stockholm, Sweden approved the study (Diary nr. 2013/497-32)

Provenance and peer review Not commissioned; externally peer reviewed.

Data sharing statement No additional data are available.

Open Access This is an Open Access article distributed in accordance with the Creative Commons Attribution Non Commercial (CC BY-NC 4.0) license, which permits others to distribute, remix, adapt, build upon this work noncommercially, and license their derivative works on different terms, provided the original work is properly cited and the use is non-commercial. See: http:// creativecommons.org/licenses/by-nc/4.0/

\section{REFERENCES}

1. Ford ES, Bergman M. Healthy living is the best revenge; findings from the European Prospective Investigation into Cancer and Nutrition-Postdam study. Arch Intern Med 2009;169:1355-62.

2. Pronk NP, Lowry M, Kottke TE, et al. The association between optimal lifestyle adherence and short-term incidence of chronic conditions among employees. Popul Health Manag 2010;13:289-95.

3. Towfighi A, Markovic D, Ovbiagele B. Impact of a healthy lifestyle on all-cause and cardiovascular mortality after stroke in the USA. J Neurol Neurosurg Psychiatry 2012:83:146-51.

4. Ford ES, Bergmann MM, Boeing $\mathrm{H}$, et al. Healthy lifestyle behaviors and all-cause mortality among adults in the United States. Prev Med 2012;55:23-7.

5. Chow CK, Jolly S, Rao-Melacini P, et al. Association of diet, exercise, and smoking modification with risk of early cardiovascular events after acute coronary syndromes. Circulation 2010;121:750-8.

6. Hoy D, Bain C, Williams G, et al. A systematic review of the global prevalence of low back pain. Arthritis Rheum 2012;64:2028-37.

7. Hoy D, Brooks P, Blyth F, et al. The epidemiology of low back pain. Best Pract Res Clin Rheumatol 2010;24:769-81.

8. Hayden JA, Chou R, Hogg-Johnson S, et al. Systematic reviews of low back pain prognosis had variable methods and results: guidance for future prognosis reviews. J Clin Epidemiol 2009;62:781-96.

9. Iles RA, Davidson M, Taylor NF, et al. Systematic review of the ability of recovery expectations to predict outcomes in non-chronic non-specific low back pain. J Occup Rehabil 2009;19:25-40.

10. Verkerk K, Luijsterburg PA, Miedema HS, et al. Prognostic factors for recovery in chronic nonspecific low back pain: a systematic review. Phys Ther 2012;92:1093-108.

11. Hendrick P, Milosavljevic S, Hale L, et al. The relationship between physical activity and low back pain outcomes: a systematic review of observational studies. Eur Spine J 2011:20:464-74.

12. Messing K, Stock SR, Tissot F. Should studies of risk factors for musculoskeletal disorders be stratified by gender? Lessons from the 1998 Quebec Health and Social Survey. Scand J Work Environ Health 2009;35:96-112.

13. Chenot JF, Becker A, Leonhardt C, et al. Sex differences in presentation, course, and management of low back pain in primary care. Clin J Pain 2008;24:578-84.

14. Bohman $\mathrm{T}$, Alfredsson $\mathrm{L}$, Hallqvist $\mathrm{J}$, et al. The influence of self-reported leisure time physical activity and the body mass index on recovery from persistent back pain among men and women: a population-based cohort study. BMC Public Health 2013;13:385

15. Svensson AC, Fredlund $P$, Laflamme $L$, et al. Cohort profile: the Stockholm Public Health Cohort. Int J Epidemiol 2013;42:1263-72.

16. Kuorinka I, Jonsson B, Kilbom A, et al. Standardised Nordic questionnaires for the analysis of musculoskeletal symptoms. Appl Ergon 1987;18:233-7.

17. The National Board of Health and Welfare (Socialstyrelsen). Nationella riktlinjer för sjukdomsförebyggande metoder 2011-stöd för styrning och ledning (National guidelines for disease prevention methods 2011). Stockholm, Sweden 2011;16-7, http://www. socialstyrelsen.se/publikationer2011/2011-11-11 (accessed Oct 2014)

18. World Health Organisation (WHO). Diet, nutrition and the prevention of chronic diseases, Report of the joint WHO/FAO expert consultation. WHO Technical Report Series No. 916. Geneva,
Switzerland, 2003. http://www.who.int/dietphysicalactivity/ publications/trs916/en/ (accessed Oct 2014).

19. World Health Organisation (WHO). Global recommendations on physical activity for health. Geneva, Switzerland, 2010. http://www. who.int/dietphysicalactivity/factsheet_recommendations/en/ (accessed Oct 2014).

20. Andreasson S, Allebeck P. Alkohol och Hälsa. Swedish National Institute of Public Health (Statens Folkhälsoinstitut) Stockholm, Sweden: r 2005:11. http://www.folkhalsomyndigheten.se/publiceratmaterial/publikationer/Alkohol-och-halsa/ (accessed Oct 2014).

21. Dionne CE, Dunn KM, Croft PR, et al. A consensus approach toward the standardization of back pain definitions for use in prevalence studies. Spine (Phila Pa 1976) 2008;33:95-103.

22. Palmlof $\mathrm{L}$, Skillgate $\mathrm{E}$, Alfredsson $\mathrm{L}$, et al. Does income matter for troublesome neck pain? A population-based study on risk and prognosis. J Epidemiol Community Health 2012;66:1063-70.

23. Carroll LJ, Hogg-Johnson S, van der Velde G, et al. Course and prognostic factors for neck pain in the general population: results of the Bone and Joint Decade 2000-2010 Task Force on Neck Pain and Its Associated Disorders. Spine 2008;33(4 Suppl):S75-82.

24. McDowell I. Measuring health a guide to rating scales and questionnaires. 3rd edn. Oxford University Press, 2006.

25. Goldberg DP, Gater R, Sartorius N, et al. The validity of two versions of the GHQ in the WHO study of mental illness in general health care. Psychol Med 1997;27:191-7.

26. Unden AL, Orth-Gomer K. Development of a social support instrument for use in population surveys. Soc Sci Med 1989;29:1387-92.

27. Statistics Sweden. Socioekonomisk indelning (SEI) (socio-economic classification system). In: Fastbom L. Meddelanden $i$ samordningsfrågor för Sveriges officiella statistik (MIS). rep No. 1982:4:6-8. Stockholm: 1984. http://www.scb.se/sv_/Hitta-statistik/ Publiceringskalender/Visa-detaljerad-information/?PublObjld=6607 (accessed Oct 2014).

28. Statistics Sweden. Longitudinal Intergration data base for health insurance-and laubormarket studies (LISA). 2009. http://www.scb. se/lisa/ (accessed Oct 2014).

29. Carroll LJ, Hurwitz EL, Cote P, et al. Research priorities and methodological implications: the Bone and Joint Decade 2000-2010 Task Force on Neck Pain and Its Associated Disorders. Spine 2008;33(4 Suppl):S214-20.

30. Kurth T, Sonis J. Assessment and control of confounding in trauma research. J Trauma Stress 2007;20:807-20.

31. Tong IS, Lu Y. Identification of confounders in the assessment of the relationship between lead exposure and child development. Ann Epidemiol 2001;11:38-45.

32. Rothman KJ, Greenland S, Lash TL. Modern epidemiology. 3rd edn. Wolters Kluwer Health/Lippincott Williams \& Wilkins, 2008.

33. Mickey RM, Greenland S. The impact of confounder selection criteria on effect estimation. Am J Epidemiol 1989;129:125-37.

34. Hosmer DW, Lemeshow S. Applied logistic regression. 2nd edn. Wiley, 2000.

35. Orsini N, Bellocco R, Bottai M, et al. Validity of self-reported total physical activity questionnaire among older women. Eur J Epidemiol 2008;23:661-7.

36. Romelsjo A, Leifman $\mathrm{H}$, Nystrom $\mathrm{S}$. A comparative study of two methods for the measurement of alcohol consumption in the general population. Int J Epidemiol 1995;24:929-36.

37. Sepp H, Ekelund U, Becker W. Enkätfrågor om kost och fysisk aktivitet bland vuxna-Underlag till urval av frågor $\mathrm{i}$ befolkningsinriktade enkäter. Swedish National Food Administration, rep No. 21; 2004. http://www.slv.se/sv/grupp1/Mat-och-naring/ Matvanor-undersokningar/Hur-undersoks-matvanor/Valideradeenkatfragor-om-kost-och-fysisk-aktivitet/ (accessed Oct 2014).

38. Ekelund U, Sepp H, Brage S, et al. Criterion-related validity of the last 7-day, short form of the International Physical Activity Questionnaire in Swedish adults. Public Health Nutrition 2006;9:258-65.

39. Connor Gorber S, Schofield-Hurwitz S, Hardt J, et al. The accuracy of self-reported smoking: a systematic review of the relationship between self-reported and cotinine-assessed smoking status. Nicotine Tob Res 2009;11:12-24.

40. Ainsworth BE, Levy SS. Methodological issues. In: Oja P, Borms J, eds. Health enhancing physical activity. Meyer \& Meyer Sport, 2004:230-69.

41. Dyrstad SM, Hansen BH, Holme IM, et al. Comparison of self-reported versus accelerometer-measured physical activity. Med Sci Sports Exerc 2014;46:99-106. 